\title{
Regression and Simulation Models for Human and Baboon Brain Parameters
}

\author{
Modelo Regresivo y Simulación para los Parámetros Cerebrales Humanos y del Babuino
}

*Ganesh Pokhariyal \& ** Jameela Hassanali

\begin{abstract}
POKHARIYAL, G. \& HASSANALI, J. Regression and simulation models for human and baboon brain parameters. Int. J. Morphol., 29(3):971-977, 2011.

SUMMARY: The variations in morphometric parameter of mammalian brains may be influenced by process of functional complexity, evolution and adaptation. Comparative analysis of linear measurements of cerebrum in the human and baboon has shown morphometric differences. In the present study linear measurements from human and baboon cerebrum ( $\mathrm{n}=10$ each) were used to predict various values for human and baboon brain and body parameters through multiple regression models. The average brain weights were found to be $2.08 \%$ and $0.84 \%$ of the body weights for humans and baboons respectively. The elasticity of regression models revealed that unit percentage increase in Occipital-Frontal (OF) distance would increase the human brain weight by $66.19 \%$, while the baboon brain weight would increase by $7.63 \%$. The unit percentage increase in the Height of Temporal Lobe (HTL) would increase the human brain weight by $16.28 \%$, while the baboon brain weight would increase by only $0.28 \%$. Unit percentage increase in Frontal-Temporal (FT) distance would decrease the human and baboon brain weights by $14.04 \%$ and $0.46 \%$ respectively. Inter-species values were also predicted through simulation techniques by using the ratios of model parameters with application of programming language Python. The OF, FT and HTL values for human were found to be 2.01 times, 1.55 times and 1.91 times respectively to that of baboon.
\end{abstract}

KEY WORDS: Morphometric parameters; Human; Baboon; Brains; Regression and simulation models.

\section{INTRODUCTION}

Brains of mammals vary in size and shape, but have similar basic structural organization consisting of cerebrum, cerebellum and brain stem (Bear et al., 2001). The variations in the size of the whole brain, its components as well as their morphology in different species appear to be influenced by the process of functional complexity, evolution and adaptations (Bear et al.; Clark et al., 2001). Adult human brain weighs on average $1.4 \mathrm{~kg}$ which is about $2 \%$ of the total body weight, while the average adult baboon brain weigh $137 \mathrm{~g}$, which is nearly $1 \%$ of the total body weight (Blinkov \& Glezer, 1968). Cerebellum constitutes nearly $13 \%$ of the weight of the human brain and coordinates body movements, posture and balance. Brain stem is nearly $2 \%$ of the weight of the human brain and connects the cerebrum, cerebellum and spinal cord and has vital centers (Zigmond et al., 1999).

The cerebrum has sulci and gyri with lobes having functional localization and constitutes nearly $85 \%$ of the weight of a human brain. The cerebral hemispheres are involved in all the voluntary (conscious) activities of the body, intelligence, learning and memory in the human. The right hemisphere is associated with creativity and artistic ability while the left hemisphere is associated with analytical and mathematical ability. The left hemisphere is more dominant in humans and has relatively higher values of the parameters (Blinkov \& Glezer).

The size and structure of the frontal, parietal, temporal and occipital lobes are associated with the functional complexity of the mammals (Bear et al.). Primate brains have large sensory, motor parietal, visual occipital and prefrontal cortex. The human brain function may have evolved by development of new brain areas or by modification of the pre-existing areas or systems, most notable being the language area (Zigmond et al.; Allmann, 2000). Comparing human and non-human brains is complicated because the knowledge is based on use of

\footnotetext{
* School of Mathematics and School of Medicine, University of Nairobi, Nairobi, Kenya.

** Department of Human Anatomy, School of Medicine, University of Nairobi, Nairobi, Kenya.
} 
different techniques. Gross brain morphology may allow non-invasive method to evaluate increase in brain size related to body size in association with functional complexity and evolution (Zigmond et al.). Comparative analysis of selected linear measurements of cerebrum from lateral, superior and inferior aspects for humans and baboons has been conducted to show morphometric differences (Hassanali et al., 2007).

Encephalization quotients (EQs) are widely used measures of relative brain size that take this empirical relationship between brain and body size into account. They are simply the ratio of a species' actual brain size to the brain size expected for an animal of its body size. Jerison (1973) used mammals as the comparison group, but one can estimate EQs, for example, on the basis of primates only. Human brain sizes are not explained by brain/body scaling in either mammals or primates (Schoenmann, 2006). Body size and weight have been associated with size of brain, but this relationship has not been explicitly expressed (Clark et al.; Kass, 2000).

Through regression models and simulating techniques an attempt can be made to establish a relationship between the brain and body parameters. Simulation modeling is a process which starts and ends with gaining insight about the systems. The abstraction allows a model to represent complexities of the real world process, device or concept. The structure of the relationship between real and conceptual worlds is basically a part of scientific method which involves data collection, such that investigators get appraisal of the real world, understanding the observations and analyzing the situation. Models are predictors of future or values that also test the validity and consistency of observation. Simulation models are described by means of mathematical symbols and involve step by step segmental calculations where the workings of systems or large scale problems can be reproduced. The input data in a simulation model may be real or generated. Multiple regression models predict the values of dependent variable involved with more than one independent variable (Murthy et al., 2000).

The model's two activities, validation and application occur during software development. Model validation involves retrospectively demonstrating that model consistently predicts actual values with acceptable accuracy. The validation of simulation is conducted for the same reason as the rerunning of the actual experiments. The process of validation often assists in gaining the insights which are then used to modify the models. The simulation process changes to reflect the improvement in the understanding of the model. The modeling aspect asks and answers questions about a system using a particular paradigm, while the validation answers the question regarding the accuracy in which models reflect objective observations (Stevenson, 1999). The present study aims at using the linear measurement of human and baboon brains to predict, through regression models and simulation methods, various values for human and baboon brains and body parameters.

\section{MATERIAL AND METHOD}

Brains. Ten human and ten baboon formalin fixed brains obtained from the Department of Human Anatomy and the Institute of Primate Research respectively, were used for this study. Three human and three baboon brains were separated into components of the cerebral hemispheres, cerebellum and brain stem. The components were weighed and mean values for the whole brains and components were obtained. The linear measurements taken from the lateral, superior and inferior aspects were analyzed in the previous study (Hassanali et $a l$.). For the present study 3 human and 2 baboon brain data was added to the previous sample.

Linear measurements. The following linear measurements (cm) were done as shown in figures 1, 2 and 3 from lateral, superior and inferior aspects respectively.

\section{Lateral Aspects (Fig.1)}

Occipital- Frontal (O-F): The distance between the poles of the occipital and frontal lobes (length).

Occipital-Temporal (O-T): The distance between the poles of the occipital and temporal lobes.

Frontal-Temporal (F-T): The distance between the poles of the frontal and the temporal lobes.

Height of Temporal lobe (HTL): The perpendicular distance from the point $(\mathrm{X})$ where the central sulcus $(\mathrm{CS})$ meets the lateral sulcus(LS) to the inferior margin of the temporal lobe(Y).

Superior Aspect (Fig.2)

Inter-Frontal (F-F): The distance between the poles of the frontal lobes

Inter-Parietal (P-P) Maximum distance between the parietal lobes (width)

Inter-Occipital (O-O): The distance between the poles of the occipital lobes.

Inferior Aspect (Fig.3)

Inter-Temporal (T-T): The distance between the right and left temporal lobes.

Inter-Occipital (OL-OL): Maximum distance between occipital lobes.

Modeling Procedure. The need assessment was conducted to determine the simulation and modeling functions that were required by the user from the system. It was found that the users need to: (i) view the analytic data in 3-D representation, zoom, rotate features and graphs (ii) determine the existence of relationships between brain parameters and (iii) simulate other measurements from the available data. 

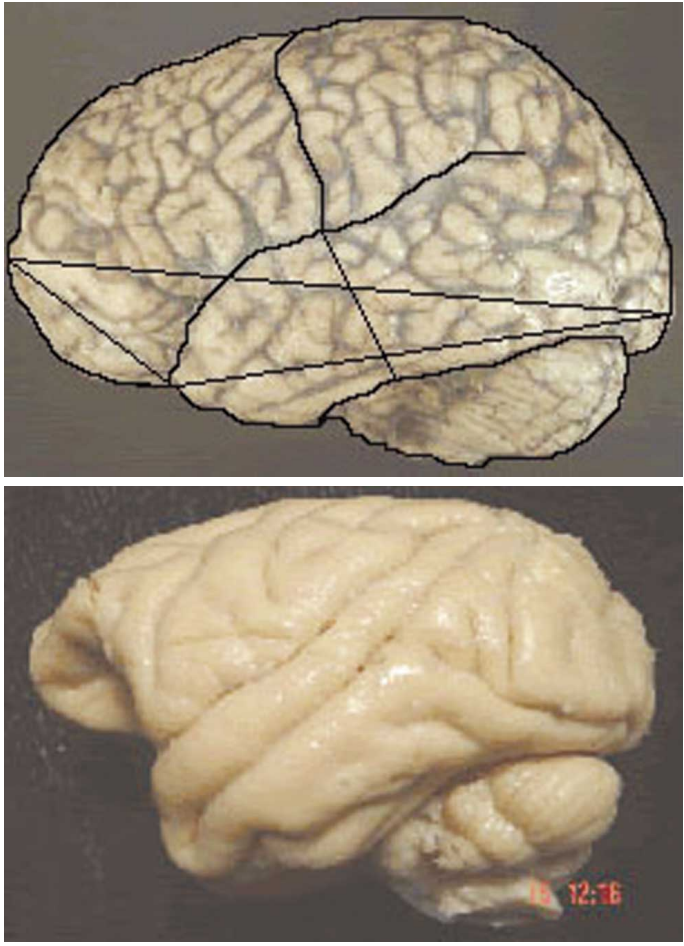

Fig. 1. A. Lateral aspect human brain; B. Lateral aspect baboon brain.
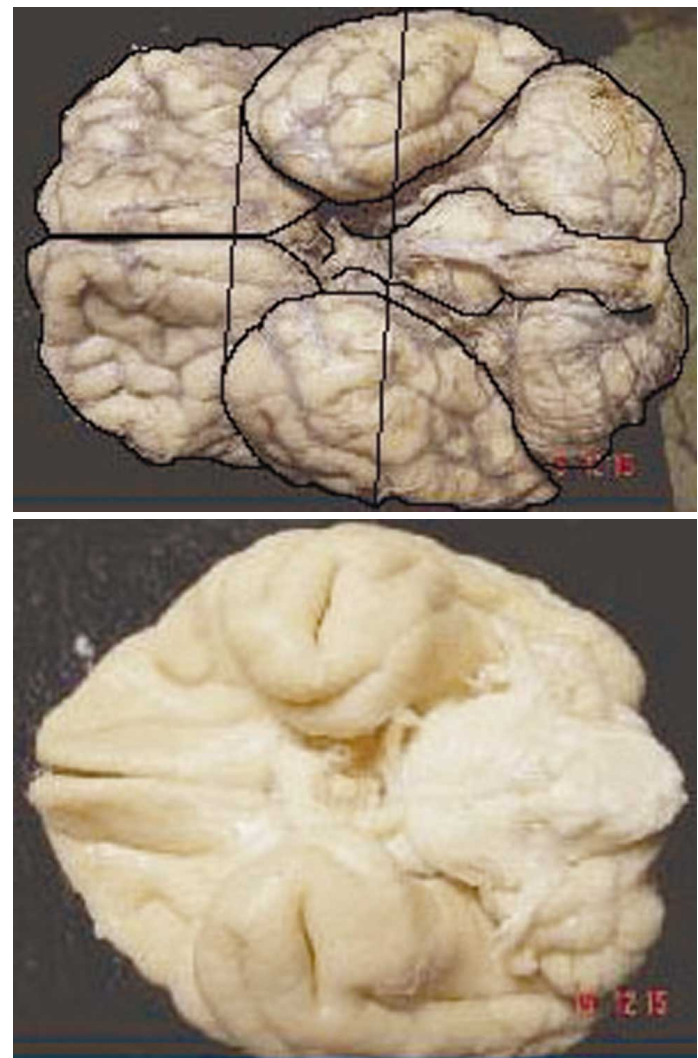

Fig. 3. A. Inferior aspect human brain; B. Inferior aspect baboon brain.
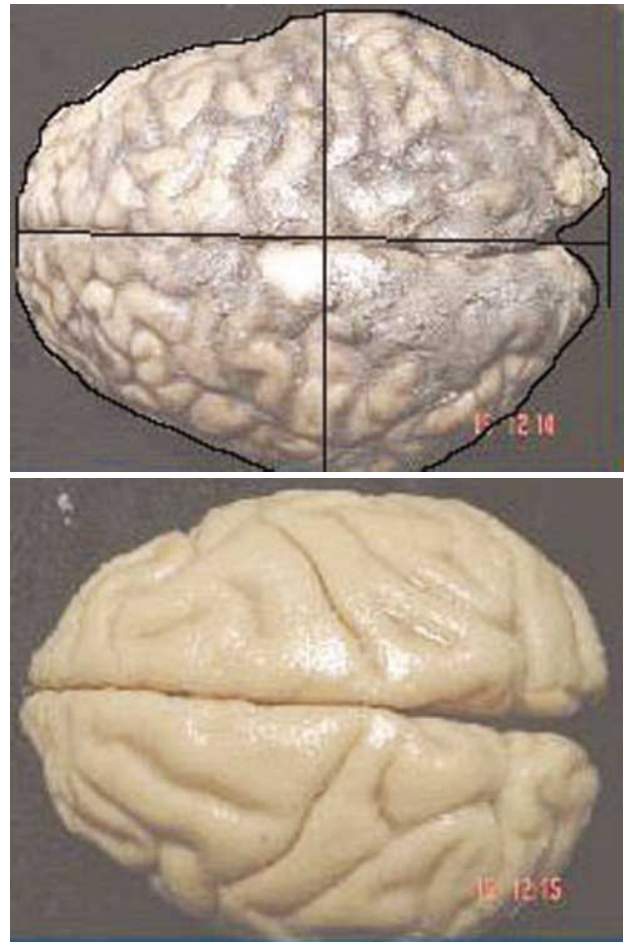

Fig. 2. A. Superior aspect human brain; B. Superior aspect baboon brain.

The corresponding tools were accordingly developed and the context diagrams were then drawn. The collected data was stored in simple text files. Design of interface layouts dealing with structuring data entry, collecting data input, feedback and help were done. Designing the dialogue sequence, building a prototype and assessing its usability were accomplished.

A multiple regression model was used to estimate brain weights using OF, FT, OT and HTL as explanatory variables, for both human and baboon subjects. The statistical significance of each of the coefficient of the model parameters was investigated. Cross species simulations were conducted, using the ratios of the model parameters, for computing the human and baboon values. The programming language Python was used, which is considered compact and extensible. The simulations were conducted using Intel Pentium IV, 1.7 Ghz with 256 MB RAM having hard disk space of $40 \mathrm{~GB}$.

\section{RESULTS}

The average brain weight for human was found to be nearly $2.08 \%$ of the body weight, where as the average baboon brain weight was found to be nearly $0.8384 \%$ of the 
body weight. The mean length (OF) and width (P-P) of human brain were found to be in the ratio of 1.3077, where as for baboon brain this ratio was 1.25.

Table I (a) shows brain weight and the values of OF $\left(x_{1}\right)$, FT $\left(x_{2}\right)$, OT $\left(x_{3}\right)$ and HTL $\left(x_{4}\right)$ for human. 1(b) shows the coefficients of regression model and $t$ values for the human.
Table I a. Brain weight (g) and mean-sd (cm) for human.

\begin{tabular}{lccc}
\hline & Mean & Std. Deviation & $\mathrm{N}$ \\
\hline Brain weight y & 1329.8502 & 37.61378 & 10 \\
\hline OF X1 & 17.05 & .64 & 10 \\
FT X2 & 5.974 & .7938 & 10 \\
OT X3 & 13.052 & .4500 & 10 \\
HTL X4 & 4.4289 & .321785 & 10
\end{tabular}

Table I b. Coefficients of regression model, and t-values for human.

\begin{tabular}{cccccc}
\hline & Un-standardized Coefficients & Standardized Coefficients & $\mathrm{t}$ & Sig. \\
\hline Model & & Beta & \\
(Constant) & 203.332 & Std. Error & & .678 & .528 \\
OF X1 & 66.190 & 299.962 & 1.128 & 4.320 & .008 \\
FT X2 & -14.043 & 15.323 & -.296 & -.848 & .435 \\
OT X3 & .744 & 16.556 & .009 & .063 & .953 \\
HTL X4 & 16.280 & 11.904 & .139 & .734 & .496 \\
\hline \multicolumn{7}{c}{ Dependent variable: Brain Weight y }
\end{tabular}

The multiple regression equation estimating the brain weight $(\mathrm{Y})$ of human was obtained as

$Y=66.19 x_{1}-14.043 x_{2}+0.744 x_{3}+16.28 x_{4}+203.332$

Table II (a) shows brain weight and values of OF $\left(x_{1}\right)$, FT $\left(x_{2}\right)$, OT $\left(x_{3}\right)$ and HTL $\left(x_{4}\right)$ for baboon. 2(b) shows the coefficients of regression model and $t$ values for the baboon.
Table II a. Brain weight $(\mathrm{g})$ and mean-sd $(\mathrm{cm})$ for baboon.

\begin{tabular}{lccc}
\hline & Mean & Std. Deviation & $\mathrm{N}$ \\
Brain weight & 113.3669 & 2.89372 & 10 \\
OF X1 & 8.49338 & .40081 & 10 \\
FT X2 & 3.865067 & .351346 & 10 \\
OT X3 & 6.7168 & .3143026 & 10 \\
HTL X4 & 2.32828 & .2538265 & 10 \\
\hline
\end{tabular}

Table II b. Coefficients of regression model and t-values for baboon.

\begin{tabular}{cccccc}
\hline & Un-standardized Coefficients & & $\begin{array}{l}\text { Standardized } \\
\text { Coefficients }\end{array}$ & $\mathrm{t}$ & Sig. \\
\hline Model & & Std. Error & Beta & & .000 \\
(Constant) & 51.503 & .216 & & 238.110 & .000 \\
OF X1 & 7.629 & .122 & 1.057 & 62.752 & .006 \\
FT X2 & -.456 & .101 & -.055 & -4.497 & .053 \\
OT X3 & -.270 & .107 & -.029 & -2.516 & .007 \\
HTL X4 & .277 & .063 & .024 & 4.372 & \\
\hline
\end{tabular}

The corresponding multiple regression equation for estimating brain weight of baboon was obtained as

$$
Y=7.629 x_{1}-0.456 x_{2}+0.27 x_{3}+0.277 x_{4}+51.503
$$

It was observed that OF $\left(x_{1}\right)$ and $\operatorname{HTL}\left(x_{2}\right)$ contribute positively where as FT contributes negatively towards the brain weight for both humans and baboons. The OT $\left(x_{3}\right)$ contributes negatively for baboon and positively for human brain weight. The corresponding elasticity of the explanatory variables was found to be quite high for humans in comparison to baboons. The $t$-test showed that for human data only $\mathrm{OF}\left(x_{1}\right)$ was found to be statistically significant. Thus the amended regression was obtained as 


$$
Y=56.48 x_{1}+3.66 .86
$$

Similarly $t$-statistics showed that for baboon data except OT $\left(x_{3}\right)$ all other variables were significant in estimating the brain weight. Thus, the amended regression using $\mathrm{OF}\left(x_{1}\right)$, FT $\left(x_{2}\right)$ and HTL $\left(x_{4}\right)$ was found to be

$$
Y=7.34 x_{1}-0.23 x_{2}+0.15 x_{4}+51.56
$$

Estimation of brain weight. By using the mean values of the parameters the brain weights for human and baboon were estimated. Using (3.1), the human brain weight was found to be

$$
\begin{gathered}
Y=66.19(17.05)-14.043(5.974)+0.744(13.052)+ \\
16.28(4.4289)+203.332=1329.792 \mathrm{~g}
\end{gathered}
$$

Using (3.3) which contains statistically significant parameter, the estimated brain weight for human was obtained as:

$$
Y=56.48(17.05)+366.86=1329.844 \mathrm{~g}
$$

Using (3.2), the baboon brain weight was found to be

$$
\begin{gathered}
Y=7.629(8.49338)-0.456(3.865067)-0.27(6.7168)+ \\
0.277(2.32828)+51.503=113.367923 \mathrm{~g}
\end{gathered}
$$

Using (3.4) which contains statistically significant parameters, the brain weight for baboon was estimated as:

$$
\begin{gathered}
Y=7.34(8.49338)-0.23(3.865067)+0.15(2.32828)+ \\
51.56=113.3616858 \mathrm{~g}
\end{gathered}
$$

The elasticity of the model parameters revealed that, the unit percentage increase in OF and HTL would increase the human brain weight by $66.19 \%$ and $16.28 \%$ respectively. Similarly unit percentage increase in $\mathrm{OF}$ would increase the baboon brain weight by $7.629 \%$ whereas unit percentage increase in HTL would increase the baboon brain weight by only $0.277 \%$. On the other hand, unit percentage increase in FT would decrease the human and baboon brain weights by $14.043 \%$ and $0.456 \%$ respectively. However, the unit percentage increase in OT would increase human brain weight by $0.744 \%$, where as the unit percentage increase in OT decrease baboon brain weight by $0.27 \%$.

Error of estimation. The estimated brain weights of human and baboon obtained through respective regression lines are compared with the mean weights obtained from data values to compute error of estimation. Using (3.1), the estimation error was found to be $-0.0044 \%$, while using (3.3), the estimation error was $-0.0005 \%$ for human brain weight. While using (3.2), the estimation error was found to be $0.0009 \%$, while using (3.4) the estimation error was $0.0046 \%$ for baboon brain weight.

Simulation Model. The ratios between linear measurements for human and baboon as well as cross species ratios were computed. These ratios were then used to simulate brain weights for human and baboon. The following results were obtained from the simulation models.

$$
\begin{aligned}
& \text { Human } \mathrm{OF}=2.85 \text { human FT }=3.84 \text { human HTL } \\
& \text { Human } \mathrm{OF}=2.01 \text { baboon OF } \\
& \text { Human FT }=1.55 \text { baboon FT } \\
& \text { Human HTL }=1.91 \text { baboon HTL }
\end{aligned}
$$

Using baboon $\mathrm{OF}$, the human $\mathrm{OF}$ was found to be Human $\mathrm{OF}=(8.49) 2.01=17.0649$

Using the equation (3.3) and above simulated value, the human brain weight was obtained as:

$$
\begin{aligned}
\text { Human brain weight } & =56.48(17.0649)+366.86 \\
& =1330.685552 \mathrm{~g}
\end{aligned}
$$

The study established that the average brain weight to body weight ratios for human and baboon came out to be:

Bodyweight $=\frac{\text { Brainweight }}{0.0211}$ and Bodyweight $=\frac{\text { Brainweight }}{0.0084}$ respectively.

Thus, these ratios were used to estimate the body weights, once the simulated brain weights were found. Using the ideal height-weight tables the approximate height range for humans could be estimated.

Similarly the baboon brain weight was estimated using (3.4) from the simulated human brain parameters as follows:

$$
Y=7.34\left(\frac{\text { Human } O F}{2.01}\right)-0.23\left(\frac{\text { Human } F T}{1.55}\right)+0.15\left(\frac{\text { Human } H T L}{1.91}\right)+51.56=7.34\left(\frac{17.05}{2.01}\right)-0.23\left(\frac{5.974}{1.55}\right)+0.15\left(\frac{4.428913}{1.91}\right)+51.56=113.2835449 \mathrm{~g}
$$




\section{DISCUSSION}

It was noticed that OF $\left(x_{1}\right)$ and HTL $\left(x_{4}\right)$ values contributed positively and the elasticity of these parameters indicated the extent of increases in the human and baboon brain weights. The increase in $\mathrm{OF}$ for humans was found to be contributing about 66 times to the increase in the brain weight as compared to nearly 7 times in the baboon case. The increase in HTL contributed only nearly 16 times for human brain weight compared to nearly one-fourth times for baboon brain weight. It was found that FT $\left(x_{2}\right)$ contributed negatively towards the brain weights for both humans and baboon, with a decrease of nearly 14 times for human case in contrast to nearly one-fourth times for baboon case. The value OT $\left(x_{3}\right)$ contributed, positively for human brain weight at the rate of nearly three fourth of a percentage, while negatively for baboon brain weight at the rate of nearly one fourth of a percentage. The errors of estimation were found to be almost negligible for all cases. These parameters can further be used to estimate the brain weights as well as body weights for human and baboon subjects individually and across species through simulation model

The comparative aspects of the selected linear parameters in the antero-posterior, lateral and inter frontal, temporal and occipital planes reflects on the enlargements of the lobes and functional areas of the cerebrum (Hassanali et $a l$.). The most obvious evolutionary change during human evolution has been an increase in both absolute and relative brain size. Estimated brain sizes of our closest living relatives, the pongids are as follows: Common Chimpanzee $337( \pm 16)$ $c c$; Pygmy Chimpanzee $311( \pm 11) c c$; Gorilla $397( \pm 67) c c$ and Orangutan $407( \pm 29) c c$ (Rilling \& Insel, 1999; Rilling, 2006). Modern human brain size vary widely, but average $\approx 1330 \mathrm{cc}$, which is 3.1 times larger than predicted on the basis of primate brain/body size allometric scaling (Schoenemann).

The comparative morphometric aspects in the anteroposterior, lateral and inter frontal, temporal and occipital planes in the human and baboon reflect on the enlargements of surfaces and size of the lobes and functional areas of the cerebrum (Rilling \& Seligman, 2002). Temporal lobe plays a critical role in auditory information as well as memory, emotion and conceptual understanding. It also plays an important role in language processing. Humans have significantly larger overall volumes, white-matter volumes and surface areas of their temporal lobes than predicted on the basis of ape scaling relationships. This suggests an elaboration in humans of the connectivity mediated in this lobe (Schoenemann). The inter-temporal poles and inter occipital lobes were found to be double for humans as compared to baboons (Hassanali et al.).
Frontal and parietal lobes contain a number of different functional areas, including the primary motor area, which directly controls conscious muscle movement; the pre-motor area, which plans complex muscle movement sequences. Prefrontal cortex mediates a number of higher cortical functions important for planning, language and social interactions, as well as having a general executive oversight of other brain regions. Morphology and convolutions of the primate cerebal cortex may be shaped by the tensions exerted by the corticocortical connections (Hilgetag \& Barbas, 2006).

The human frontal cortical gray matter is 3.6 time larger, while the frontal gyral white matter is 4.7 times larger than the average for their pongid sample. This suggests a bias towards white matter expansion in humans, although the extent to which this is explained statistically by allometric frontal/non-frontal scaling cannot be determined. However, the increased frontal lobe (by more than 3 times) is likely due to important behavioral and functional implications of some kind (Schoenemann). Inter frontal linear measurements increased six fold in humans as compared to baboons (Hassanali et al.).

The frontal lobes in the humans have enlarged proportional to the parietal, temporal and occipital lobes (FF, FT). The parietal lobes are central for orientation, object identification, recognition and conscious perception as well as motor and sensory function (P-P). Compared to the baboons, humans have the speech (HTL) and visual cortex with functional complexity of associated visual cortex (OL), inter occipital (O-O) and (T-T). The evolutionary trends in brain size and weights in primates and hominids have shown relative changes in cortical functional areas reflecting on the selected linear parameters considered in the regression model.

With advances in brain imaging techniques, data is emerging on the functional complexity and specialization of cerebral areas in the human. However, morphometry and analysis allows for a non-invasive method to study the functional and evolutional changes in the primates and hominids (Zigmond et al.). This model can be tested using parameters of other non-human primates to estimate brain weight, body weight and height. It can be useful in estimating parameters of hominids and humans from brain or endocasts.

ACKNOWLEDGEMENTS. We thank the Institute of Primate Research and Department of Human Anatomy for providing the fixed human and baboon brains and Mwasina K. Patience for computational formatting. 
POKHARIYAL, G. \& HASSANALI, J. Modelo regresivo y simulación para los parámetros cerebrales humanos y del babuino. Int. J. Morphol., 29(3):971-977, 2011.

RESUMEN: Las variaciones en los parámetros morfométricos del cerebro de los mamíferos pueden estar influenciadas por el proceso de complejidad funcional de la evolución y adaptación. Análisis comparativo de las mediciones lineales del cerebro en el humano y babuino han puesto de manifiesto las diferencias morfométricas. En este estudio las mediciones lineales del cerebro humano y babuinos ( $\mathrm{n}=10$ cada uno) fueron utilizados para predecir los valores distintivos para el cerebro de humanos y monos babuinos y los parámetros del cuerpo a través de modelos de regresión múltiple. El peso medio del cerebro resultó ser 2,08\% y 0,84\% del peso corporal de los seres humanos y los babuinos, respectivamente. La elasticidad de los modelos de regresión reveló que el aumento de una unidad porcentual en la distancia occipital-frontal (DE) aumentaría el peso del cerebro humano en 66,19\%, mientras que el peso del cerebro babuino se incrementaría en 7,63\%. El porcentaje de aumento en la altura de lóbulo temporal (HTL) aumentaría el peso del cerebro humano en 16,28\%, mientras que el peso del cerebro babuino aumentaría en sólo el 0,28\%. Si aumenta la distancia frontal-temporal (FT) se reduciría el peso del cerebro humano y babuinos en 14,04\% y 0,46\%, respectivamente. También se prevéen valores entre las especies a través de técnicas de simulación, mediante el uso de proporciones de los parámetros del modelo con la aplicación del lenguaje de programación Python. Los valores humanos de DE, FT y HTL resultaron ser 2,01, 1,55 y 1,91 veces, respectivamente con respecto a la de los babuinos.

PALABRAS CLAVE: Parámetros morfométricos; Humano; Babuino; Cerebros; Regresión y modelos de simulación.

\section{REFERENCES}

Allmann, J. Evolving Brains. New York, W. H. Freeman \& Co., 2000.

Bear, M. F., Connors, B. W. \& Paradiso M. A. Fundamentals of Neuroscience. Exploring the brain. $2^{\text {nd }}$ ed. Baltimore, Lippincott Williams and Wilkins, 2001.

Blinkov, S. M. \& Glezer I. I. The Human Brain in Figures and Tables. Basic Books Inc. New York, Plenum Press, 1968.

Clark, D. A., Mitra, P. P. \& Wang S. S. Scalable architecture in mammalian brains. Nature, 411:89-193, 2001.

Hassanali, J.; Pokhariyal, G. \& Mwasina, P. Comparative analysis of selected linear measurements of human and baboon brains. Eur. J. Anat., 11:9-16, 2007.

Hilgetag, C. \& Barbas, H. Role of mechanical factors in the morphology of the primate cerebal cortex. PLoS Comput. Biol., 2(3):e22, 2006.

Kaas, J. H. Why is brain size so important: design problems and solutions as neocortex gets bigger or smaller. Brain and Mind., 1:7-23, 2000.

Jerison, H. J. Evolution of the Brain and Intelligence. New York and London, Academic Press, 1973.

Murthy, D. N. P.; Page, N. W. \& Rodin, E. T. Mathematical Modelling. New York, Pergaman Press, 2000.

Rilling, J. K. Human and non human primate brains: Are they allometrically scaled versions of the same design? Evol. Anthrol., 15:65-77, 2006.
Rilling, J. K. \& Insel, T. R. Evolution of neocortical size and gyrification in hominids: Evidence from comparative neuroanatomy. Am. J. Phys Anthrol., (Suppl.28):233, 1999. (Abstract).

Rilling, J. K. \& Seligman, R. A. A quantitative morphometric comparative analysis of the primate temporal lobe. J. Hum. Evol., 42:505-33, 2002.

Schoenemann, P. T. Evolution of the size and functional areas of the human brain. Annu. Rev. Anthropol. 35:379-406, 2006.

Stevenson, D. E. A Critical look at quality in large-scale simulations. Compu. Sci. Eng., 1:53-63, 1999.

Zigmond, M. J.; Bloom, F. E.; Landis, S. C.; Roberts, J. L. \& Squire, L. R. Fundamentals Neuroscience. New York, Academic Press, 1999.

Correspondence to:

Prof. Jameela Hassanali

Department of Human Anatomy

School of Medicine

University of Nairobi

Nairobi,

KENYA

Tel.: +25402 442368;

Fax: +254 02335372

E-mail: jali@uonbi.ac.ke

Received: 23-02-2011

Accepted: 28-04-2011 